\title{
A New Approach To Particulate Measurement On Transient Test Cycles: Partial Flow Dilution As Alternative to CVS Full Flow Systems
}

Thomas Schweizer

Swiss Federal Laboratories for Materials Testing and Research (EMPA)

H. Jürgen Stein

DaimlerChrysler AG

Reprinted From: Emission Measurement and Testing

(SP-1503) 
The appearance of this ISSN code at the bottom of this page indicates SAE's consent that copies of the paper may be made for personal or internal use of specific clients. This consent is given on the condition, however, that the copier pay a $\$ 7.00$ per article copy fee through the Copyright Clearance Center, Inc. Operations Center, 222 Rosewood Drive, Danvers, MA 01923 for copying beyond that permitted by Sections 107 or 108 of the U.S. Copyright Law. This consent does not extend to other kinds of copying such as copying for general distribution, for advertising or promotional purposes, for creating new collective works, or for resale.

SAE routinely stocks printed papers for a period of three years following date of publication. Direct your orders to SAE Customer Sales and Satisfaction Department.

Quantity reprint rates can be obtained from the Customer Sales and Satisfaction Department.

To request permission to reprint a technical paper or permission to use copyrighted SAE publications in other works, contact the SAE Publications Group.

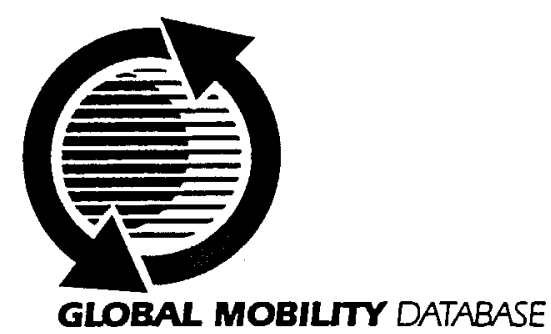

All SAE papers, standards, and selected books are abstracted and indexed in the Global Mobility Database

No part of this publication may be reproduced in any form, in an electronic retrieval system or otherwise, without the prior written permission of the publisher.

\section{ISSN 0148-7191}

Copyright @ 2000 Society of Automotive Engineers, Inc.

Positions and opinions advanced in this paper are those of the author(s) and not necessarily those of SAE. The author is solely responsible for the content of the paper. A process is available by which discussions will be printed with the paper if it is published in SAE Transactions. For permission to publish this paper in full or in part, contact the SAE Publications Group.

Persons wishing to submit papers to be considered for presentation or publication through SAE should send the manuscript or a 300 word abstract of a proposed manuscript to: Secretary, Engineering Meetings Board, SAE.

\section{Printed in USA}




\title{
A New Approach To Particulate Measurement On Transient Test Cycles: Partial Flow Dilution As Alternative to CVS Full Flow Systems
}

\author{
Thomas Schweizer \\ Swiss Federal Laboratories for Materials Testing and Research (EMPA) \\ H. Jürgen Stein \\ DaimierChrysier AG
}

Copyright $(92000$ Society of Automotive Engineers, Inc.

\begin{abstract}
In a subproject of the aim to develop a worldwide certification procedure for heavy-duty on-highway engines (WHDC), the measuring technique for future low emitting engines was evaluated. One aspect is the introduction of partial flow dilution systems for the particulates measurement during transient test cycles instead of the currently required full flow dilution systems.
\end{abstract}

This paper presents an investigation about the influence of sensitive sampling parameters on particulate mass and composition under steady state and transient engine operating conditions, and their effect on the correlation between partial flow and full flow dilution systems.

The study has shown that the sampling parameters investigated have no or only minor influence on particulate mass and composition. Both partial flow dilution systems proved their transient capability by tracking the exhaust flow signal very well. Overall no consistent and statistically significant difference between the test results obtained with the full flow CVS system and the two partial flow systems was observed.

\section{INTRODUCTION}

The United Nations ECE (Economic Commission for Europe) GRPE (Group of Rapporteurs on Pollution and Energy), responsible for vehicle exhaust emissions regulations, has mandated the subgroup WHDC (Worldwide Heavy Duty Certification) to develop a worldwide harmonized exhaust emissions test procedure for heavy duty on-highway engines used in trucks and buses, in order to remove differences in environmental regulations between countries and world markets.
As regards the emission measurement procedure, the objective of the work is the development of an ISO standard on cost effective and accurate exhaust emissions measurement systems. The task will mainly focus on verifying partial flow dilution and raw exhaust gas measurement, well established procedures for steady state test cycles $[1,2]$ ", for use on transient cycles as an alternative to the currently required full flow systems [3]. The resulting ISO standard could be applied to any transient test cycle in place today or projected for the future.

For the principle investigations and the correlation studies, external research programs were conducted, whose results will be used in establishing the ISO standard. This paper contains the results of the first study, which mainly deals with investigations on particulate measurement.

First of all, the influence of sensitive sampling parameters, which are defined in todays exhaust emissions regulations $[1,2,3]$, on particulate mass and composition during transient test cycles was investigated. The correlation between partial and full flow systems depends to a certain degree on the definition of those parameters. Since these definitions might not be appropriate for future low emitting engines, they were investigated in a dedicated parameter study on the basis of the future European test procedures [4].

\footnotetext{
"Numbers in parentheses indicate References at end of paper
} 


\section{TEST PROGRAM}

\section{PARTICULATE MEASUREMENT}

During the complete investigation, three particulate measuring units were run in parallel: a state of the art CVS full flow system as reference system and two partial flow systems provided by AVL (Smart Sampler SPC 472 [5]) and by Control Sistem (PSS-20). Their transient capability was checked by comparing the sample flow rate to the exhaust flow rate. The two traces must coincide very closely in order to enable proportional sampling. Figure 1 shows for the PSS 20 that this condition was met during a portion of the European Transient Cycle (ETC).

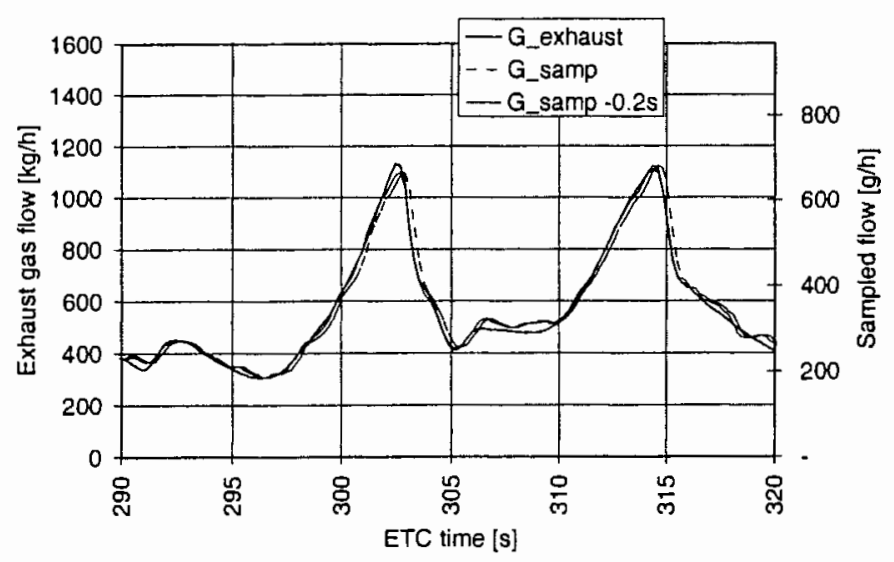

Figure 1: Transient sampling during the ETC (Control Sistem PSS-20)

For the complete cycle, the proportionality was proven by a linear regression between sample probe and exhaust flow signals (see table 1).

\begin{tabular}{|l|c|c|}
\hline Regression data* & AVL & Control Sistem \\
\hline SE (\% of max.) & $2.71 \ldots 4.08$ & 2.49 \\
\hline Slope $r$ & $0.62 \ldots 0.93$ & 0.60 \\
\hline$R^{2}$ & $0.94 \ldots 0.99$ & 0.97 \\
\hline$Y$ intercept $[\mathrm{g} / \mathrm{sec}]$ & $-0.002 \ldots 0.002$ & 0.0024 \\
\hline
\end{tabular}

* $\left[G_{\text {exhaust }}\right]=\mathrm{kg} / \mathrm{h},\left[G_{\text {proba }}\right]=g / h$

Table 1: Regression analysis between sample probe and exhaust gas flow (ETC)

The parameters, which may have an influence on the measuring result, can be differentiated into those, which apply to partial flow systems only, such as

- Diameter of the sample line

- Length of the sample line

- Temperature of the sample line

- Location of the sampling probe
And those, that apply to both partial and full flow systems, such as

- Heating/insulation of the dilution tunnel

- Sampling zone temperature (dependent variable)

- Filter face temperature

- Filter face velocity

- Pressure drop over filter (dependent variable)

- Dilution ratio

- Mixing procedure between exhaust gas and dilution air

- Temperature and humidity of the dilution air

- Filter loading

- Filter collecting characteristics

Since the test bed equipment of the engine lab did not allow to perform all the above mentioned variations, the following test programm for the first study was elaborated in the responsible ISO working group (ISO TC 22/SC 5/WG 2):

Pretests had to be be carried out in order to determine, whether the muffler or the connection of the CVS full flow system has an influence on the measuring results. Also, it was verified, that both partial flow systems were operating well together and did not influence each other.

For the single mode measurements, the measuring points $A 100, C 75$ and $B 100$ of the European Steady State Cycle ESC were selected.

\section{Pretests:}

1) With/without muffler

3 single modes, ESC, ETC

2) One partial flow system only

3) With/without CVS full 3 single modes, ESC, ETC flow system

After the pretests, the layout of the exhaust gas tube and the sampling probe location was defined for the parameter study.

During the parameter study, the following parameters were decided to be investigated (reference conditions in bold type): 


\section{Parameter study:}

4) Dilution factor $(4 / 6 / 8 / 12)$

5) Filter face velocity ( 30 / 50/max. possible [cm/s])

6) Filter loading $(0.25 / 0.5 / 1$ [mg])

7) Sample line temperature $\left(150 / 200\left[{ }^{\circ} \mathrm{C}\right]\right)$

8) Tunnel heating (insulated/ insulated and heated to $\left.50^{\circ} \mathrm{C}\right)$

9) Sample line length (0/0.5/1.5 [m])

10) Sample line diameter (10/4 [mm])
6 single modes, ETC

6 single modes, ETC

6 single modes, ETC

6 single modes, ETC

6 single modes, ETC

6 single modes, ETC

6 single modes, ETC

\begin{tabular}{|lcc|}
\hline properties & units & analysis \\
\hline Cetane number & - & 56.3 \\
\hline Density $\left(@ 15^{\circ} \mathrm{C}\right)$ & $\mathrm{kg} / \mathrm{m}^{3}$ & 820.0 \\
\hline Viscosity $\left(@ 40^{\circ} \mathrm{C}\right)$ & $\mathrm{mm}^{2} / \mathrm{s}$ & 2.29 \\
\hline Sulphur content & $\mathrm{ppm}$ & 20 \\
\hline Total aromatics content & $\mathrm{Vol} \%$ & 12.1 \\
\hline Flash point & ${ }^{\circ} \mathrm{C}$ & 83.0 \\
\hline HFRR-Test (@ $\left.60^{\circ} \mathrm{C}\right)$ & $\mathrm{micron}$ \\
\hline
\end{tabular}

Table 2: Fuel specifications, EMPA analysis

\section{TEST RESULTS}

The ESC modes A100, C75, B100, B50 and B25 served for the single mode measurements, completed with the point B10 (10\% load at ESC speed B), which was chosen to represent frequent part load conditions during ETC. The ESC test was well enough represented by the single mode measurements.

To enable a minimum statistical assessment of the measuring results, each measurement was repeated three times.

\section{ENGINE, FUEL AND TEST BENCH}

The engine used in this program was a Mercedes OM 501 LA, supplied by DaimlerChrysler. It was a turbocharged, intercooled engine $(12 l, V 6)$ with unit pump injection. The maximum power was $260 \mathrm{~kW}$ at $1800 \mathrm{rpm}$. The engine was especially tuned to reach a particulate emission level below the proposed EURO III limits.

The diesel fuel had to fulfil important specifications of the planned EURO IV legislation or of the world-wide fuel charter (category 3 ) of the engine manufacturers. Therefore, a commercially available city diesel fuel (Greenergy Diesel) was chosen with the specifications shown in table 2.

The EMPA heavy-duty test bench is made of a fixed asynchronous motor with 6-pulse static converter for four quadrant operation (Schenck Dynas, $680 \mathrm{~kW}, 2500 \mathrm{Nm}$, $4000 \mathrm{rpm}$ ). It has a speed and torque measuring unit with transducer flange and telemetric data transmission. The exhaust gas analysers are suitable for continuous measurements of raw or diluted exhaust gas (Horiba MEXA 9200 DF). The exhaust gas dilution tunnel is a full flow system with heat exchanger and positive displacement pump (Pierburg 120 WT / PS 2000).

\section{GENERAL REMARKS AND PRETESTS}

Due to the engine tuning and the use of the city diesel fuel, the particulate level of the engine was reduced to $0.04 \mathrm{~g} / \mathrm{kWh}$ on the ESC cycle and $0.07 \mathrm{~g} / \mathrm{kWh}$ on the ETC cycle. Thereby the desired low particulate level could be reached.

Since the emission level of the engine was that low, the sampling time for the originally agreed filter loading $(1 \mathrm{mg}$ ) increased to a time consuming value. In order to achieve an efficient test program, the reference filter loading of the parameter study was reduced to $0.5 \mathrm{mg}$.

Although the filter loading defined was evidently lower than the recommended minimum loading in the current EURO III draft regulation [4], the repeatability of the measurement results (test cycles) was generally good, with a standard deviation ranging between 2 and $4 \%$.

The stability of the measurement results with reference conditions had to be ensured during the whole measuring program. Therefore the reference conditions were measured three times, at the beginning, in the middle and at the end of the parameter study. During these measurements, an overall drift of the particulate emission was detected over the duration of the whole parameter study. However, this drift did not influence the results of the individual test series except for the dilution ratio study, as explained later.

\section{Test series 1: Influence of the muffler}

As shown in figure 2, the static pressure at the sampling probe location was below $10 \mathrm{hPa}$ at all ESC points except $\mathrm{C} 100$, when the muffler was installed. The pressure variations because of pulsations were below $20 \mathrm{hPa}$. Without the muffler, both values increased significantly: 
The static pressure was four to five times higher and the pressure variations were between 30 and $120 \mathrm{hPa}$ ( $1 \mathrm{hPa}$ is equal to $100 \mathrm{~Pa}$ ).

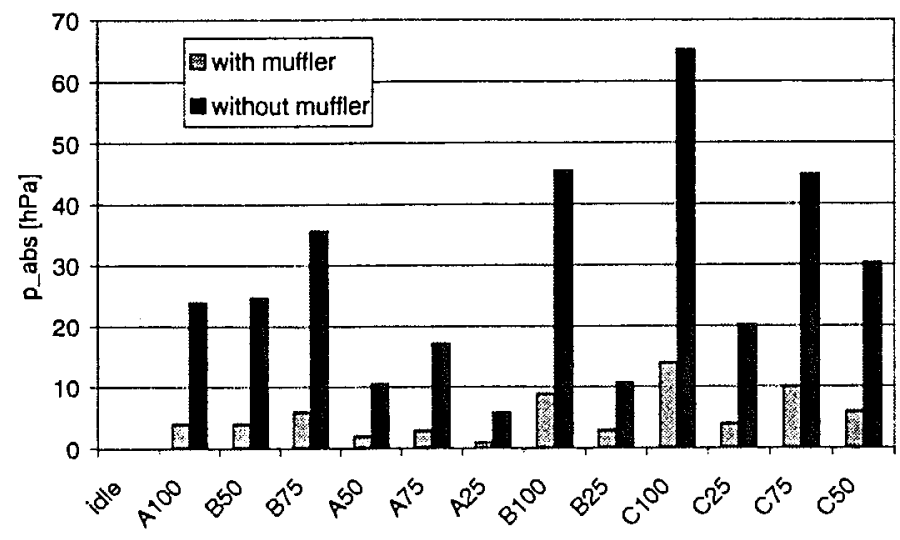

Figure 2: $\quad$ Static pressure at the sampling probe location with and without the muffler installed

Figure 3 shows the influence: Without installing the muffler, the PM level increased. This trend could be observed both with the partial flow systems and with the full flow system. With respect to the application of aftertreatment systems and the current legislation, the working group decided to do the parameter study with the muffler installed, although the muffler itself could influence the particulate emission.

The error bars in the figures represent two times the standard deviation of three individual measurements (repeatability). The average of these values is the final result (columns).

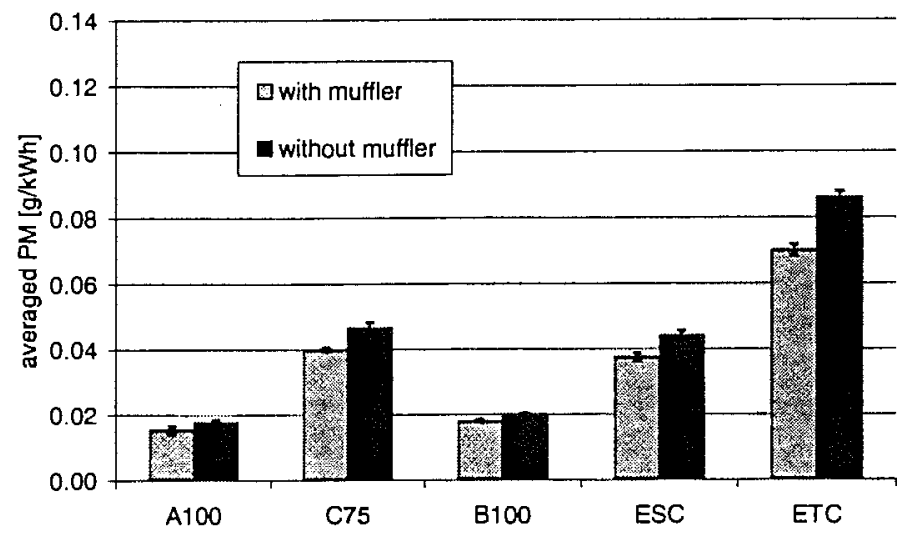

Figure 3: Influence of the muffler installed (AVL partial flow system)

\section{Test series 2: One partial flow system only}

At the beginning of the measurements, the sampling probe geometry was as follows: Both tubes were installed towards the exhaust flow, close together in the center of the exhaust gas pipe. This geometry was used for the test series 1 to 5 (see test program).

The results of the measurements with only one partial flow system demonstrated, that there was a certain difference, if one system only was installed, compared to the measurements with both partial flow systems. Probably, the two sampling probes were too close together. Therefore, the working group decided to change the sampling probe geometry to an inline setup with a distance of $500 \mathrm{~mm}$ between the two tubes. This installation was mounted from test series 6 to test series 10 .

By comparing the reference measurements with different sampling probe designs, it became clear, that the influence of the sampling probe geometry was not statistically significant.

\section{Test series 3: Influence of the CVS full flow system}

When the CVS full flow system is working, the positive displacement pump (PDP) causes a small underpressure. To ensure, that this had no influence on the measured values of the partial flow systems, tests were performed without connecting the exhaust gas tube to the CVS full flow system.

Figure 4 demonstrates, that no influence could be seen.

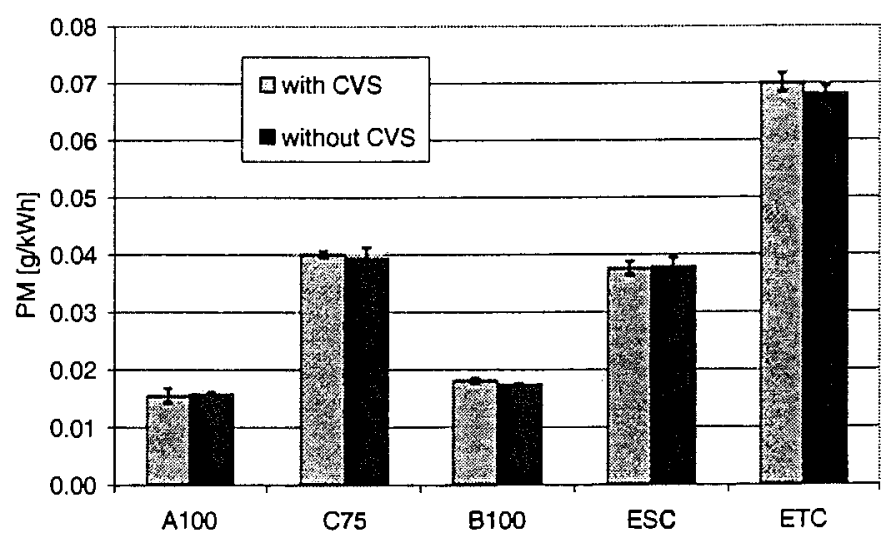

Figure 4: Influence of CVS full flow system connected on AVL values

\section{PARAMETER STUDY}

\section{Test series 4: Influence of the dilution ratio}

To check the influence of the dilution ratio on the particulate mass and composition, it was varied with each system between 4 and 12 .

For the test cycles, the adjustments of the parameters were made with the ESC mode C100. 
Because it was not possible to control the dilution air temperature and humidity of all systems, the preconditionning of the dilution air was kept constant during these tests. This means, that the filter temperature changed with the dilution ratio. These two important factors could not be considered isolatedly in this program.

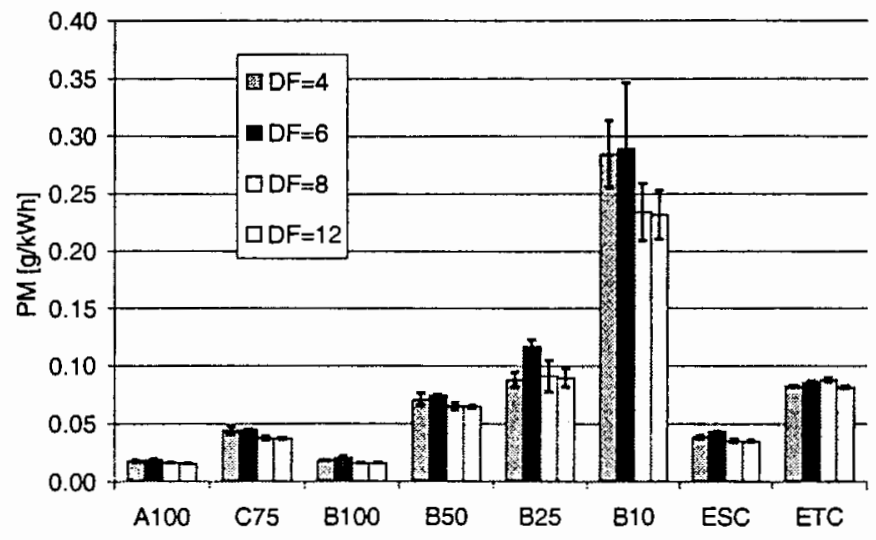

Figure 5: Influence of dilution ratio on the measuring values of the AVL system

Figures 5 and 6 show, that no trend of the PM level over a dilution ratio between 4 and 12 could be observed with either system.

It has to be mentioned, that these measurements had been done at a very low barometric pressure (945 mbar). As stated above, this influenced the measuring results to a certain degree. The particulate emission level with the standard dilution ratio of 6 was the highest in the whole measuring program. This behavior must be taken into account when assessing the influence of the dilution ratio.

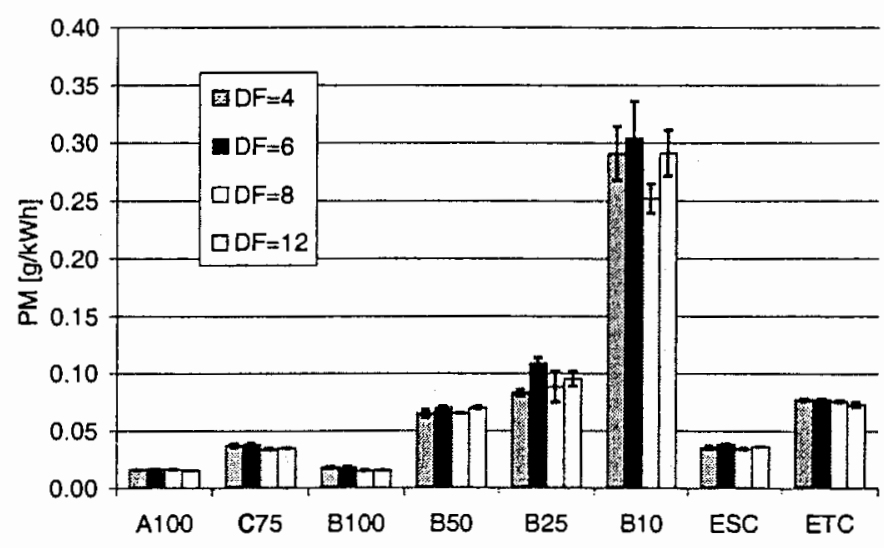

Figure 6: Influence of dilution ratio on the measuring values of the CVS full flow system
Test series 5: Filter face velocity (30/50/max. possible $[\mathrm{cm} / \mathrm{s}]]$

The range of the adjustable filter face velocity differed from system to system. The AVL system e.g. allowed only total mass flows below $2 \mathrm{~g} / \mathrm{s}$, which was equivalent to $61 \mathrm{~cm} / \mathrm{s}$ filter face velocity. With the other partial flow system (Control Sistem), velocities of $100 \mathrm{~cm} / \mathrm{s}$ and more were possible. This was the reason, why for every system the maximum possible setting had been chosen for the measurements with the high filter face velocity.

For very low emitting engines, the filter face velocity can be a solution to increase loading on the particulate filter, while the dilution ratio and the temperatures are remaining more or less constant. This is an important point to avoid the situation, that the cycle has to be repeated to get enough loading on the particulate filter.

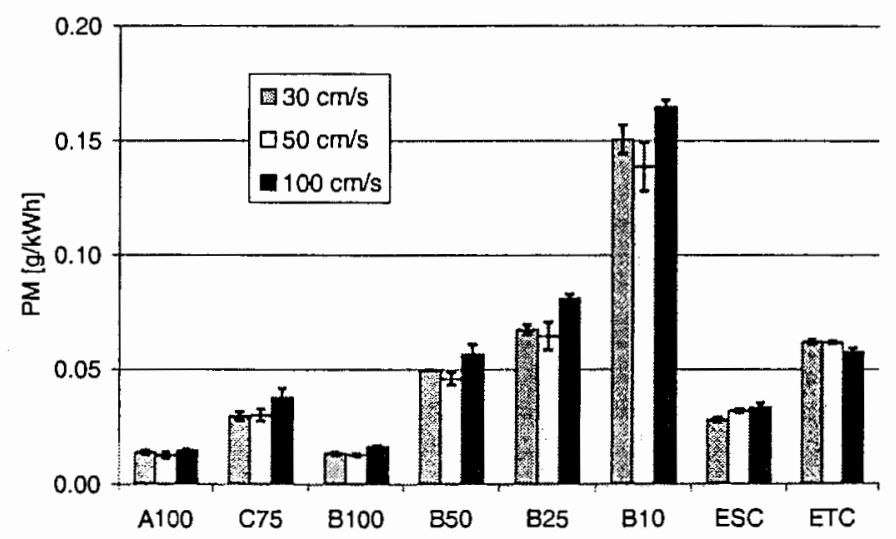

Figure 7: $\quad$ Variation of the filter face velocity with the Control Sistem unit

Figure 7 shows for the CS system that the different filter face velocities did not have a clear influence on PM emission. This result was also confirmed for the two other systems. Day-to-day variabilities in the measuring conditions had a higher influence on the results.

\section{Test series 6: Filter loading (0.25/0.5/1.0 [mal)}

The minimum recommended filter loading in the current EURO III regulation is $1.3 \mathrm{mg}$ for filters with a $70 \mathrm{~mm}$ diameter. With the engine used in this program, the filter loading in the European steady state cycle (ESC) was about $0.7 \mathrm{mg}$ at reference conditions.

To avoid expensive repetitions of the cycle, the minimum recommended filter loading has to be lowered or the exhaust gas flow over the filter has to be increased.

To detect the influence of the filter loading on the measuring results, the loading was lowered till $0.25 \mathrm{mg}$, which was only about 12 times higher than the minimum re- 
quired standard deviation of the microbalance used for weighting the particulate filters.

For very high filter loadings of several milligramms, the degree of deposition is increasing with the filter loading. For comparable measuring results, the filter loading has to be similar in this case.

With the low filter loading in this program, this trend could not be observed anymore, as shown in figure 8 . It has to be mentioned, that the standard deviation of the microbalance used in this program (Mettler MT5) was 1 microgramm.

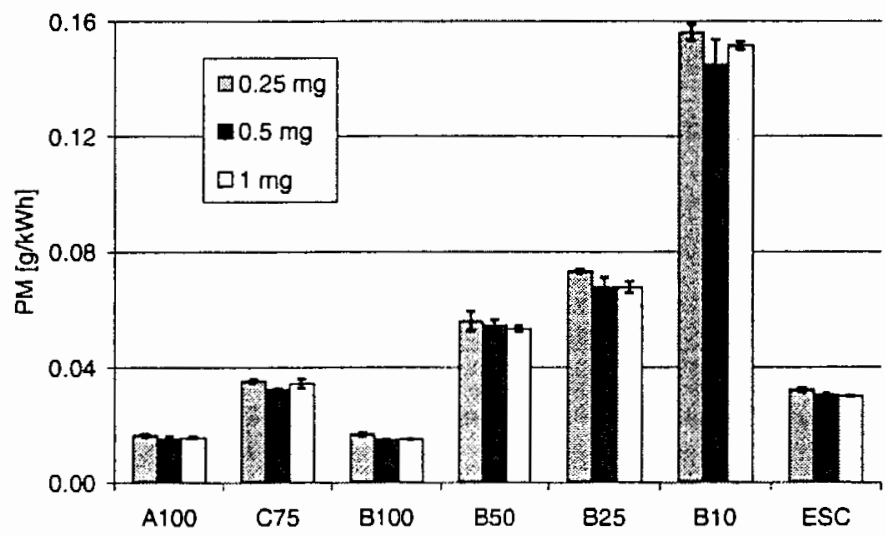

Figure 8: Influence of the filter loading (Control Sistem)

\section{Test series 7: Sample line temperature $\left(150 / 200\left[{ }^{\circ} \mathrm{C}\right]\right)$}

The temperature in the mixing zone between exhaust gas and dilution air is generally considered to be of high importance for particulate formation and measurement. The sample line heating influenced this temperature, since the tunnel inlet temperature was observed to be higher with the higher sample line temperature.

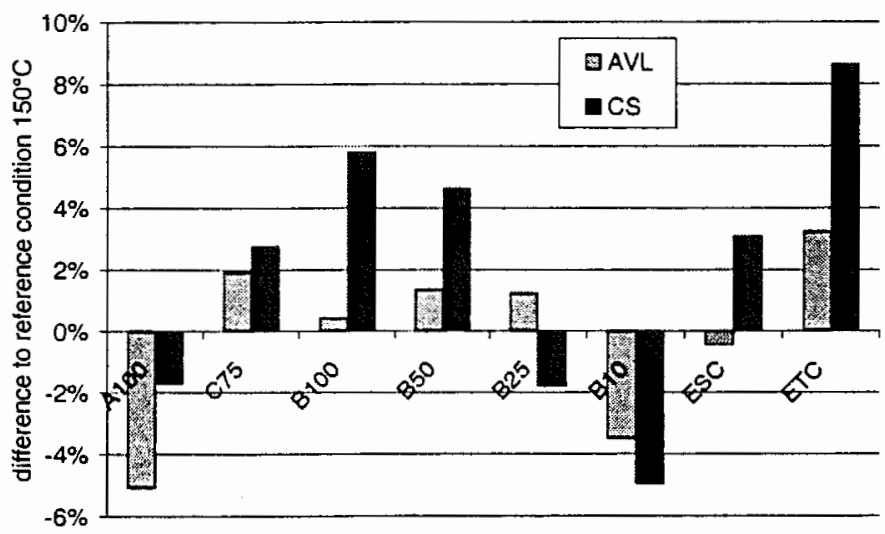

Figure 9: Sample line heating (partial flow systerns)
Figure 9 demonstrates that one partial flow system measured higher values on both test cycles with the higher sample line temperature. Nevertheless this trend was not definite: At low load of the engine (single mode B10) or in the mode A100, the opposite was observed.

Figure 10 shows that only the AVL system had an influence on the filter face temperature and also on the SOF content on the particulate filter. The other partial flow system (CS) indicated no influence on the filter face temperature, which was also reflected by the SOF content remaining constant for both sample line temperatures. The CVS full flow system measured two times the same value, which was a sign for constant environmental conditions. Therefore the conclusion can be drawn, that the sample line heating had no definite trend on the PM measurement. But basically, the individual deviations from the measurements with reference conditions were not neglectable.

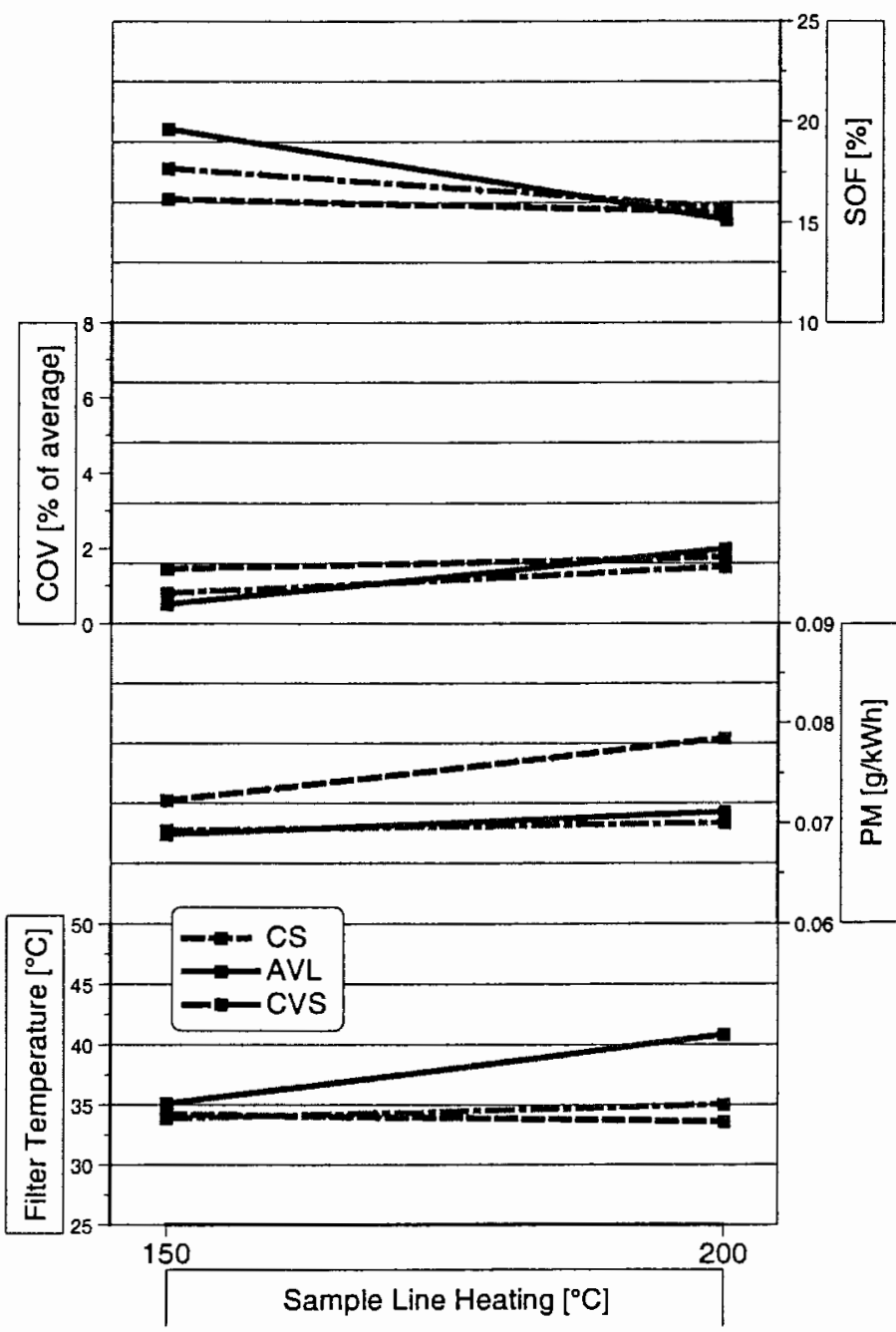

Figure 10: $\quad$ Sample line heating for ETC cycle 
Test series 8: Tunnel heating (insulated/insulated and heated $\left[50^{\circ} \mathrm{C}\right]$ )

With the tunnel heating, which had to be installed by the equipment manufacturers, a significant increase of the filter face temperature occured (see figure 11). Linked to this fact, the SOF content decreased slightly.

As shown in figure 12, the measuring results presented a lower PM level at mode B10, which was consistent with a presumably lower SOF content in this point with the tunnel heating. On the ETC, this trend was surprisingly opposite: A higher particulate emission was observed although the single mode B10 was taken into the program to simulate the frequent part load conditions during the ETC.

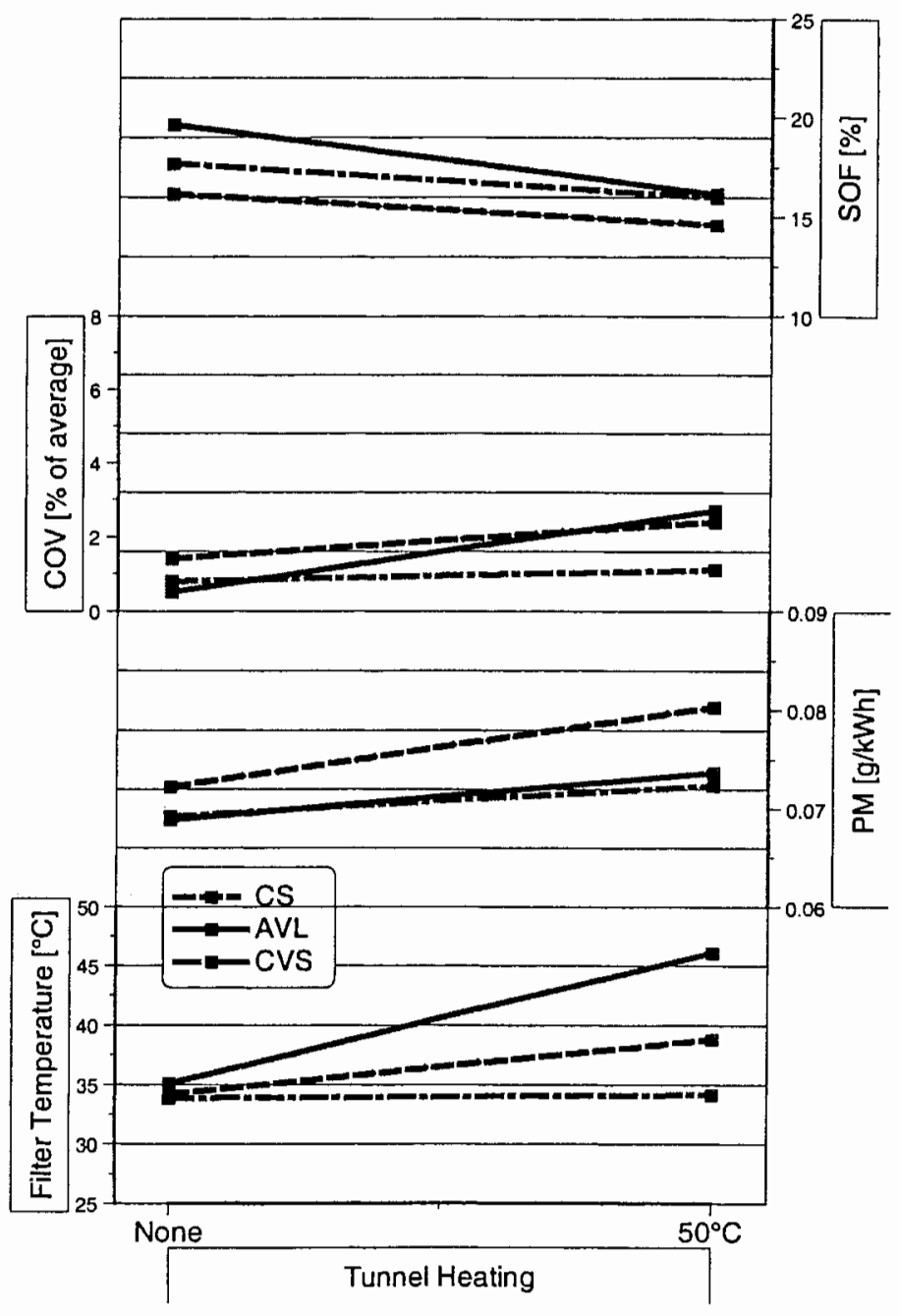

Figure 11: Influence of tunnel heating in the ETC, compared to the full flow system

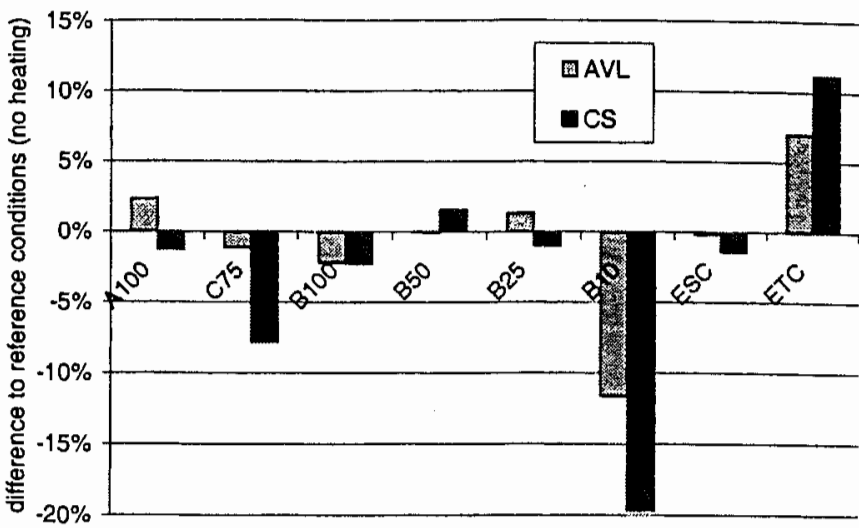

Figure 12: Tunnel heating (partial flow systems)

The CVS full flow system measured also a higher PM level during the tests with the tunnel heating (the full flow tunnel was not heated!). With that background, the ETC results did not demonstrate a significant trend for the PM measurement.

During measuring points with high engine load, the upper limit of the filter face temperature $\left(52^{\circ} \mathrm{C}\right)$ was reached or passed over.

\section{Test series 9: Sample line length $(0 / 0.5 / 1.5[\mathrm{ml})$}

Generally, the temperature level decreased with the longer sample line. With the shortest line, all partial flow systems exceeded the filter face temperature limit $\left(52^{\circ} \mathrm{C}\right)$ in some of the single modes.

The trend of lower temperatures was consistent with a significantly increasing SOF content on the ETC measurements with the longer sample lines. Simultaneously the total particulate mass decreased with longer sample lines. This indicated losses of carbonaceous particulates in the sample line, probably due to insufficient preconditioning times.

The standard deviations of the three individual ETC measurements are the lowest at reference conditions and increase for shorter and longer sample lines (see figure 13). 


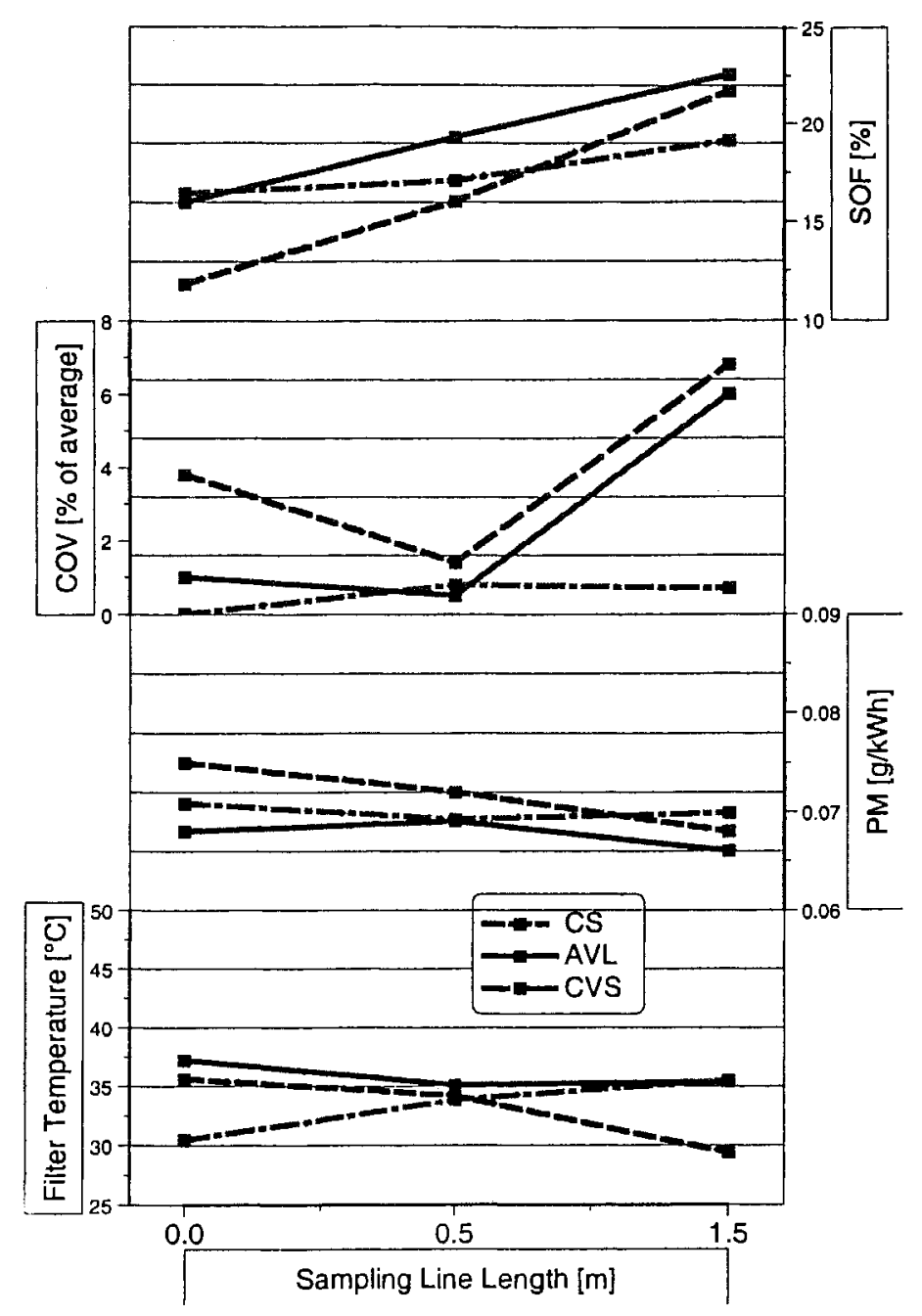

Figure 13: Influence of sample line length in ETC, compared to the full flow system

The measuring results of one partial flow system demonstrated a slight trend on the test cycles to lower particulate emissions with longer sample lines. But in some single modes, an opposite trend could be observed (see figure 14). The other partial flow system did not indicate a clear trend.

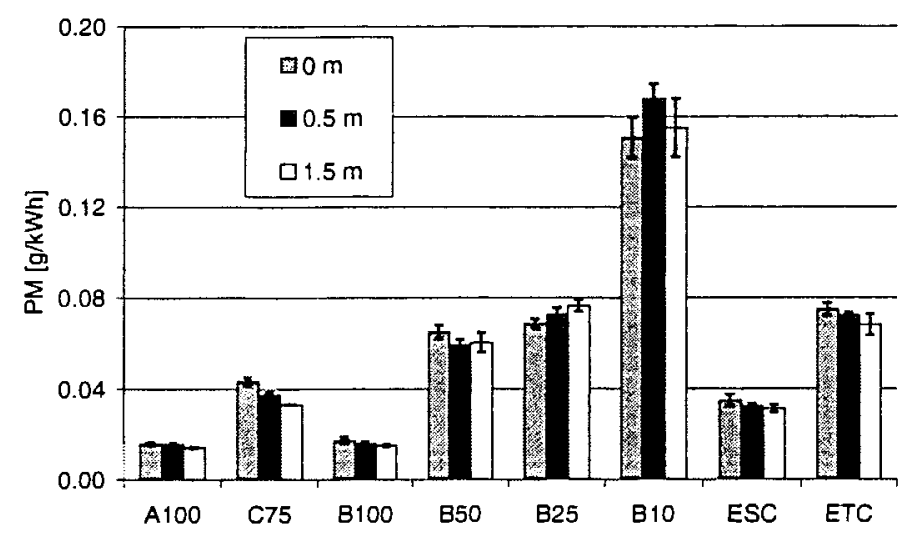

Figure 14: Influence of the sample line length (Control Sistem)

\section{Test series 10: Sample line diameter (10/4 [mm])}

When the sample line diameter was reduced from $10 \mathrm{~mm}$ to $4 \mathrm{~mm}$, the velocity of the exhaust gas in the line was six times higher than before. Figure 15 shows that the results with the smaller diameter of $4 \mathrm{~mm}$ were within $5 \%$ except for modes A 100 and C 75. Some of the equipment manufacturers claimed, that flow control within the system was better with the smaller diameter (see figure 1).

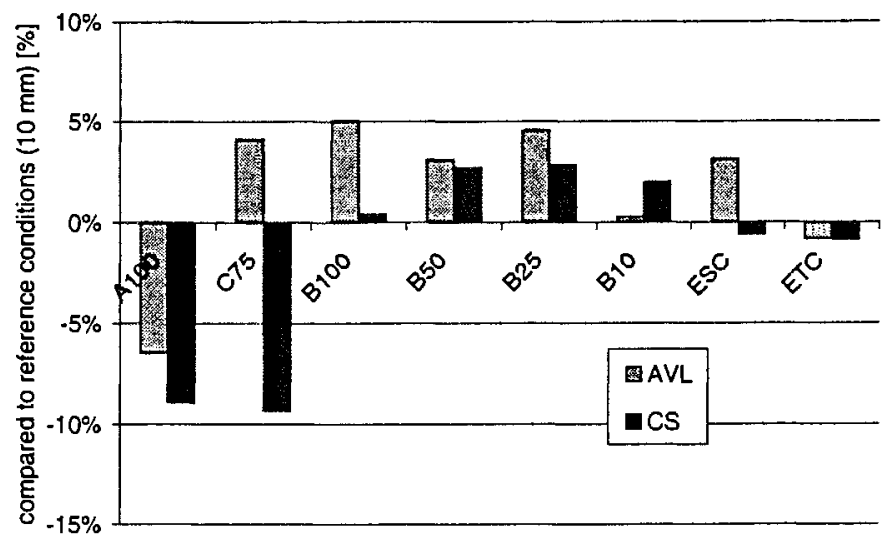

Figure 15: Influence of the sample line diameter (partial flow systems)

Despite of that statement, the standard deviation of the three individual test runs increased for both partial flow systems with the smaller diameter (see figure 16).

The SOF content (see figure 16) on the filters decreased for the partial flow systems with the smaller diameter. The filter face temperature remained constant for the AVL system, but decreased for the CS system with the smaller diameter. There was no explanation to be found for this behaviour.

Although SOF content, filter face temperature and standard deviation demonstrated some slight reactions to the smaller diameter of the sample line, there was no effect to be seen on the PM results themselves. 


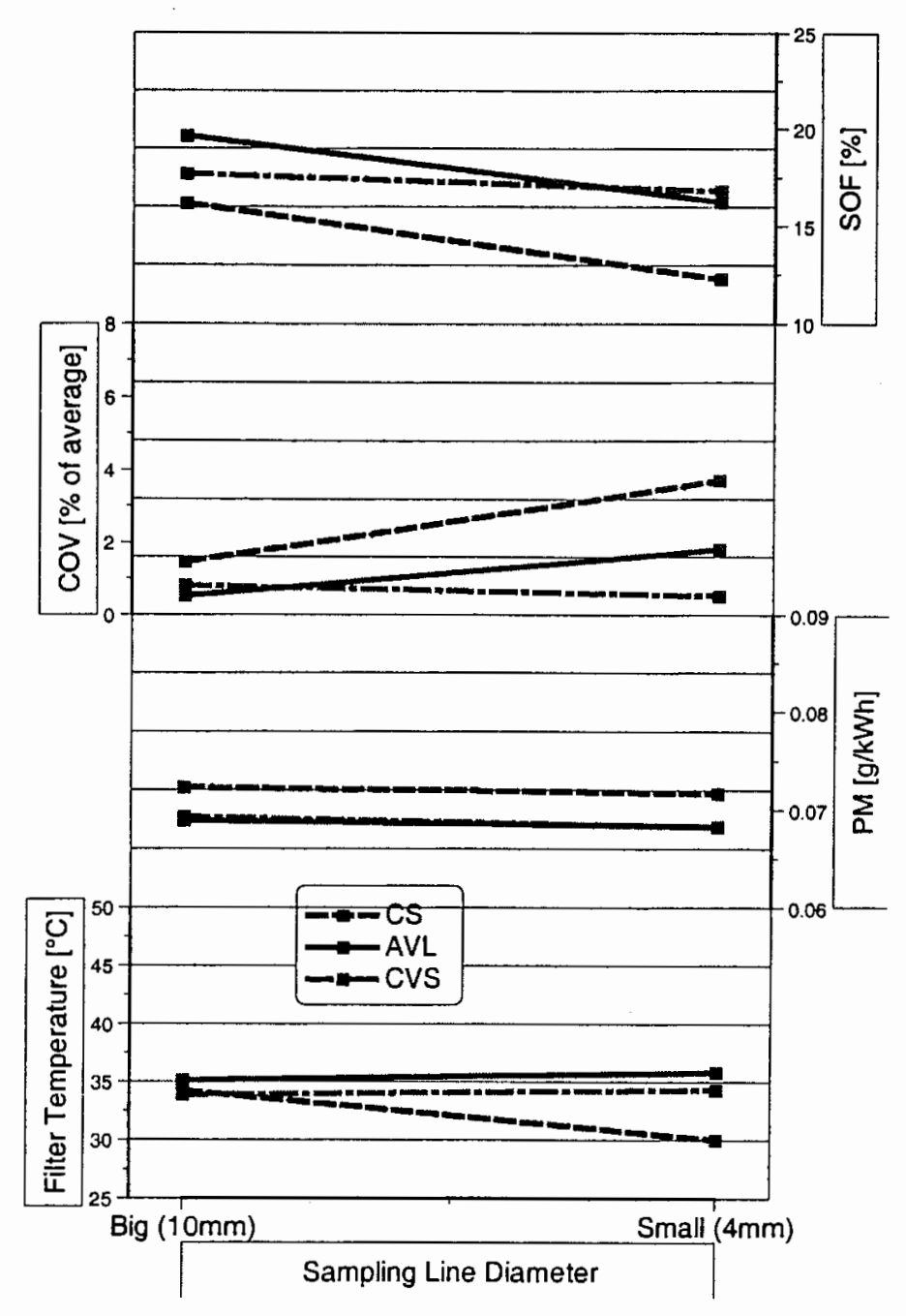

Figure 16: Influence of the sample line diameter (partial flow systems)

\section{STATISTICAL VALIDATION}

Since most of the influences reported above were only minor, a statistical validation was carried out in order to determine their significance. In a first step, the difference between the three systems over all parameters investigated was evaluated by a t-test for each test mode and cycle. This test compares the mean values of the three systems on each individual test series against each other for significant differences. A significant difference is indicated by a t-test value $>95 \%$. The results are summarized in table 3 .

\begin{tabular}{|c|c|c|c|}
\hline Mode & AVL/CVS & CS/CVS & AVL/CS \\
\hline A 100 & $99.17 \%$ & $99.98 \%$ & $87.88 \%$ \\
\hline C 75 & $20.56 \%$ & $37.57 \%$ & $53.38 \%$ \\
\hline B 100 & $41.73 \%$ & $81.09 \%$ & $54.13 \%$ \\
\hline ESC & $68.01 \%$ & $98.64 \%$ & $87.01 \%$ \\
\hline ETC & $17.93 \%$ & $40.51 \%$ & $26.30 \%$ \\
\hline
\end{tabular}

Table 3: $\quad$ T-test comparison between mean values

The t-test comparison shows that except for mode A 100 there is generally no statistically significant difference between the mean values of the systems. This is especially valid for the ETC transient cycle proving again the transient capability of the partial flow dilution systems. No explanation could be found for the differences observed with mode A 100 , but it should be noted that with this mode the absolute PM values were very low at around $0.01 \mathrm{~g} / \mathrm{kWh}$.

In a second step, the influence of the investigated sampling parameters on the PM result was tested by means of an ANOVA (Analysis of Variance). Each parameter and each test mode were analyzed separately in order to allow a more detailed picture. The results are summarized in table 4.

Statistically, the most significant parameter was the dilution ratio. This is not surprising, since it has been known that the dilution ratio can influence the soluble organic fraction of the particulates and thus the total particulate mass. However, in this study no influence was observed at mode $B 10$ with the highest soluble fraction. In addition, an overall $P M$ maximum value was observed at a dilution ratio of 6 and lower PM values at lower and higher dilution ratios, as shown in figure 5 . These results are in contradiction to current knowledge. It is therefore questionable, whether the observed significance can be attributed to the dilution ratio effect only, or whether other effects occurred in this test series, as indicated earlier.

From the other general parameters, filter face velocity and filter loading showed only very few significant effects. PM levels tended to be slightly higher at low filter face velocity and low filter loading. This finding would allow lower minimum filter loadings in future emissions regulations to take account of the low PM levels of those engines. 


\begin{tabular}{|c|c|c|c|c|}
\hline Parameter & Mode & CVS & AVL & CS \\
\hline Dilution ratio & $\begin{array}{ll}\text { A } & 100 \\
\text { C } & 75 \\
\text { B } 100 \\
\text { B } 50 \\
\text { B } 25 \\
\text { B } 10 \\
\text { ESC } \\
\text { ETC }\end{array}$ & $\begin{array}{l}- \\
\star * \\
\star * \\
* \\
* \\
\vdots \\
* \\
*\end{array}$ & $\begin{array}{l}\vdots \\
* * \\
* * \\
\vdots \\
* \\
\vdots \\
* \\
* *\end{array}$ & \\
\hline Filter face velocity & \begin{tabular}{|l} 
A 100 \\
C 75 \\
B 100 \\
B 50 \\
B 25 \\
B 10 \\
ESC \\
ETC
\end{tabular} & $\begin{array}{l}- \\
- \\
\vdots \\
\vdots \\
\vdots \\
*\end{array}$ & $\begin{array}{l}- \\
- \\
\pm \\
\pm \\
- \\
- \\
- \\
\pm\end{array}$ & $\begin{array}{l} \\
\vdots \\
* \\
* \\
- \\
- \\
*\end{array}$ \\
\hline Filter loading & \begin{tabular}{|l|} 
A 100 \\
C 75 \\
B 100 \\
B 50 \\
B 25 \\
B 10 \\
ESC \\
ETC \\
\end{tabular} & $\begin{array}{l}- \\
- \\
- \\
\vdots \\
\vdots \\
-\end{array}$ & $\begin{array}{c}* \\
- \\
* \\
- \\
* \\
- \\
* \\
- \\
\end{array}$ & $\begin{array}{l}- \\
- \\
* \\
- \\
- \\
* \\
-\end{array}$ \\
\hline Sample line temperature & $\begin{array}{ll}\text { A } 100 \\
\text { C } 75 \\
\text { B } 100 \\
\text { B } 50 \\
\text { B } 25 \\
\text { B } 10 \\
\text { ESC } \\
\text { ETC } \\
\end{array}$ & & $\begin{array}{l}- \\
- \\
- \\
- \\
- \\
- \\
-\end{array}$ & $\begin{array}{l}- \\
- \\
- \\
- \\
- \\
-\end{array}$ \\
\hline Tunnel heating & \begin{tabular}{|l} 
A 100 \\
C 75 \\
B 100 \\
B 50 \\
B 25 \\
B 10 \\
ESC \\
ETC \\
\end{tabular} & & $\begin{array}{l} \\
- \\
- \\
- \\
- \\
* * \\
- \\
*\end{array}$ & $\begin{array}{l}- \\
- \\
- \\
- \\
- \\
* \\
-\end{array}$ \\
\hline Sample line length & $\begin{array}{l}\text { A 100 } \\
\text { C 75 } \\
\text { B 100 } \\
\text { B 50 } \\
\text { B 25 } \\
\text { B 10 } \\
\text { ESC } \\
\text { ETC } \\
\end{array}$ & & $\begin{array}{l}- \\
* \\
* * \\
- \\
- \\
* \\
- \\
-\end{array}$ & $\begin{array}{l}- \\
- \\
- \\
- \\
- \\
-\end{array}$ \\
\hline Sample line diameter & $\begin{array}{ll}\text { A } 100 \\
\text { C } 75 \\
\text { B } 100 \\
\text { B } 50 \\
\text { B } 25 \\
\text { B } 10 \\
\text { ESC } \\
\text { ETC }\end{array}$ & & $\begin{array}{l}\overline{-} \\
- \\
-\end{array}$ & $\begin{array}{l}* \star \\
- \\
- \\
- \\
- \\
- \\
-\end{array}$ \\
\hline
\end{tabular}

- = non significant; ${ }^{\star}=$ significant; ${ }^{\star \star}=$ highly significant

Table 4: $\quad$ ANOVA results of parameter study

For the parameters related to partial flow dilution systems, significant effects were only observed in a few cases, and they were not consistent. PM levels tended to be slightly lower with a longer sample line, so sample lines shorter than $1.5 \mathrm{~m}$ are recommended. For sample line temperature, tunnel heating and sample line diameter the current legislative requirements seem to be acceptable.

\section{CONCLUSIONS}

Overall, the repeatability of the particulate measurement with either system is in a constant range of 5 to $10 \%$ down to low filter loadings of $0.25 \mathrm{mg}$. This applies to single mode measurements and to complete steady state and transient test cycles.

As regards the influence of the sampling parameters on the PM emission,

- no clear trend of the PM level over a dilution ratio between 4 and 12 was observed, but the interactions between filter face temperature and dilution ratio will be investigated more thoroughly in a further study;

- no significant trend of the PM level over a filter face velocity between 30 and $100 \mathrm{~cm} / \mathrm{s}$ was observed;

- no significant trend of the PM level over a sample filter loading between 0.25 and $1 \mathrm{mg}$ was observed;

- no significant influence of the sample line temperature between 150 and $200{ }^{\circ} \mathrm{C}$ on the PM level was observed;

- no consistent trend of the PM level through tunnel heating was observed, but lower PM at mode B 10 and higher PM at ETC;

- no significant influence of the sample line length was observed, but a slight tendency towards lower PM level with the $1.5 \mathrm{~m}$ sample line;

- no significant influence of the sample line diameter on the PM level was observed.

In summary, there is no statistically significant difference between the test results obtained with the full flow CVS system and the two partial flow systems over the range of parameters and test cycles investigated.The current allowable range of $P M$ sampling parameters need not be modified based on the results of the study reported in this paper, but further work is needed to confirm these findings.

\section{ACKNOWLEDGMENTS}

The authors would like to thank the International Organization of Motor Vehicle Manufacturers (OICA), for funding the study, the measuring instrument manufacturers, AVL and Control Sistem, for making available the partial flow systems free of charge, and DaimlerChrysler $A G$ for submitting the engine. The authors gratefully acknowledge the contribution of the members of the working group ISO/TC 22/SC 5/WG 2 in the design and evaluation of the test program. We also appreciate the great support and encouragement from the government members of GRPE and WHDC during the whole phase of the work program. 


\section{REFERENCES}

1. ECE Regulation No. 49, Uniform Provisions Concerning the Approval of Compression-Ignition Engines and Vehicles Equipped with CompressionIgnition Engines With Regard to the Emissions of Pollutants by the Engine, 1992

2. Council Directive 91/542/EEC on the Approximation of the Laws of the Member States Relating to the Measures To $\mathrm{Be}$ Taken Against the Emission of Gaseous and Particulate Pollutants from Diesel Engines for Use in Vehicles, 1991

3. Code of Federal Regulations, Title 40, Part 86, Subpart N - Emission Regulations for New Otto-Cycle and Diesel Heavy-Duty Engines; Gaseous and Particulate Exhaust Test Procedures, 1984

4. Common Position EC) No 35/1999 on the Approximation of the Laws of the Member States Relating to the Measures To Be Taken Against the Emission of Gaseous and Particulate Pollutants from Diesel Engines for Use in Vehicles, and amending Council Directive 88/77/EC, 1999
5. K. Engeljehringer, W. Schindler, "Experiences with a Mini-Dilution System for Engine Homologation and Development", SAE Paper 942418, 1994

\section{CONTACTS}

Thomas Schweizer

Head of Engine Testing

EMPA, Dept. IC Engines / Furnaces

Überlandstrasse 129

$\mathrm{CH}-8600$ Dübendorf

thomas.schweizer@empa.ch

http://www.empa.ch

H. Jürgen Stein

Manager Exhaust Emissions

DaimlerChrysler AG

HPC T 352

D-70546 Stuttgart

hj.stein @ daimlerchrysler.com 